\title{
Regioselective Benzylic Oxidation of Aromatic Abietanes: Application to the Semisynthesis of the Naturally Occurring Picealactones A, B and C
}

\author{
Laura E. Kolsi, ${ }^{[a]}$ Sara Krogerus, ${ }^{[a]}$ Vanessa Brito, ${ }^{[b]}$ Tobias Rüffer, ${ }^{[c]}$ Heinrich Lang, ${ }^{[c]}$ Jari Yli- \\ Kauhaluoma, ${ }^{[a]}$ Samuel M. Silvestre ${ }^{[b, d]}$ Vânia M. Moreira ${ }^{*}[a, e]$
}

\begin{abstract}
Oxygenated aromatic abietanes are an important class of naturally occurring compounds in plants where they play specific ecological roles. However, limited availability from their natural sources hampers their exploitation for the development of new drugs to treat human diseases. Herein the benzylic oxidation of aromatic abietanes mediated by sodium chlorite and aqueous tert-butyl hydroperoxide is reported. The method is regioselective for 12substituted derivatives and gives the 7-oxo products, in good yields. Moreover, it conveniently replaces the use of toxic chromium reagents for this transformation. Preparation of 7-oxo, 7-oxo-15-hydroperoxy and 7-oxo-15-hydroxy derivatives of other aromatic abietanes is also possible with this method. Furthermore, the reaction products were used as key intermediates for a short and facile semisynthesis of the naturally occurring picealactones $A, B$ and $C$ to disclose their antiproliferative activity for the first time.
\end{abstract}

\section{Introduction}

The oxidation of benzylic $\mathrm{C}-\mathrm{H}$ of aromatic abietanes such as methyl dehydroabietate $\mathbf{1}$ (Table 1) is a key chemical transformation extensively investigated in the literature. Oxygenated aromatic abietanes at positions 7 and 15 exist widely in nature and display important biological activities including, for instance, the 7-oxo compounds sugiol and salvinolone,,$^{[1]}$ the 7hydroxy aquilarabietic acids, ${ }^{[2]}$ the 7,20 -lactone carnosol ${ }^{[1]}$ or the 15-hydroxy compound angustanoic acid $\mathrm{F}^{[1]}$. Like many other natural products, they are usually not available in large amounts from nature and their difficult and expensive isolation greatly hampers the exploration of their medicinal potential. ${ }^{[3-6]}$ Instead

[a] Laura E. Kolsi, Sara Krogerus, Prof. Jari Yli-Kauhaluoma, Dr. Vânia M. Moreira

Drug Research Program, Division of Pharmaceutical Chemistry and Technology, Faculty of Pharmacy University of Helsinki

Viikinkaari 5 E (P.O. Box 56), FI-00014, Helsinki, Finland

Email: vania.moreira@helsinki.fi

[b] Vanessa Brito, Dr. Samuel M. Silvestre

Health Sciences Research Centre

University of Beira Interior (CICS-UBI)

Av. Infante D. Henrique, 6200-506 Covilhã, Portugal

[c] Dr. Tobias Rüffer, Prof. Dr. Heinrich Lang

Faculty of Natural Sciences, Institute of Chemistry, Inorganic

Chemistry

Technische Universität Chemnitz

09107 Chemnitz, Germany

[d] Dr. Samuel M. Silvestre

Centre for Neuroscience and Cell Biology (CNC)

3004-504, Coimbra, Portugal

[e] Dr. Vânia M. Moreira

Strathclyde Institute of Pharmacy and Biomedical Sciences

University of Strathclyde

161 Cathedral Street, Glasgow G4 0RE, UK their semisynthetic preparation is possible from commercially available abietanes including abietic, dehydroabietic and podocarpic acids, which are oxidized at positions 7 and 15, or by total synthesis from other compound classes. ${ }^{[1]} 7$-Oxo aromatic abietanes are also versatile building blocks for the synthesis of novel diterpenoids in search for new drug leads. ${ }^{[7,8]} 7-0 \times 0-15-$ hydroperoxy derivatives on the other hand play an important role as intermediates in the synthesis of 15-hydroxy derivatives as well as podocarpane-type diterpenoids. ${ }^{[9,10]}$

By far the most common method for preparing the 7-oxo derivative of 1 involves the use of environmentally hazardous and noxious chromium(VI) reagents ${ }^{[10-12]}$ that build up during the workup procedures, as they are typically used in great excess with large volumes of a chlorinated solvent, making these methods impractical. Other oxidation methods use hydrogen peroxide/manganese (III) porphyrin complexes, ${ }^{[13]}$ photooxidation, ${ }^{[14]}$ or ruthenium(IV) oxide. ${ }^{[15]}$ However, the former produce only low yields of the product whereas the latter does not result in a significant yield improvement, necessitates costly ruthenium reagents and produces large quantities of metal waste. Moreover, metal-based methods are plagued by possible contamination of the final products with trace metallic impurities. Additional methods to oxidize 1 include the use of $\mathrm{N}$ bromosuccinimide, which gives the 7-oxo-15-hydroxy derivative as the major reaction product, ${ }^{[16]}$ whereas under aerobic conditions using dibenzoyl peroxide ${ }^{[11,17]}$ or $N$-hydroxyphthalimide (NHPI) in combination with either metal co-catalysts or expensive $\mathrm{V}-70,{ }^{[9]}$ mixtures of the 7-oxo, 7-oxo-15-hydroxy and 7-oxo-15hydroperoxide derivatives, are obtained, in variable ratios.

Herein we report the benzylic oxidation of 1 and expand the scope of this reaction to several other dehydroabietic acid derivatives using sodium chlorite $\left(\mathrm{NaClO}_{2}\right)$ in combination with aqueous tertbutyl hydroperoxide (TBHP). Sodium chlorite is a stable oxidizing agent mainly used for the bleaching and stripping of textiles, pulp, and paper, as well as water disinfection. ${ }^{[18]}$ In organic chemistry, oxidation systems based on sodium chlorite or hypochlorite and TBHP are known as inexpensive and environmentally friendly water-based oxidation methods. ${ }^{[19,20]}$ However, their suitability for the benzylic oxidation of $\mathbf{1}$ and other aromatic abietanes remains yet unexplored. We further demonstrate the utility of this procedure for establishing a fast and reliable entry to the semisynthesis of picealactones A, B and C, scarcely available naturally occurring diterpenoids, as a means to elucidate their potential bioactivity, which remained elusive prior to this work. 


\section{Results and Discussion}

The oxidation of 1 with $\mathrm{NaClO}_{2}$ and aqueous TBHP was first examined according to the conditions reported on Table 1, Entry 1. A mixture of products was formed which could not be easily separated by column chromatography. However, it was possible to identify the 7-oxo $\mathbf{2 a}, \mathbf{1 5}$-hydroperoxy $\mathbf{2 c}$ and 15-hydroxy $\mathbf{2 d}$ derivatives. The major reaction product $2 \mathbf{a}$ was present in a mixture with the 7-hydroperoxy derivative $\mathbf{2 b}$, identified by the position of the $\mathrm{C} 7$ signal on the ${ }^{13} \mathrm{C}$ NMR spectrum at $81.5 \mathrm{ppm}$. Extension of the reaction time to three days (Table 1, Entry 2) gave products $\mathbf{2 a}, \mathbf{2 c}$ and $\mathbf{2 d}$ which were isolated by column chromatography in 39\%, 31\% and 7\% yields, respectively. Using these conditions, total consumption of the 7-hydroperoxy derivative $\mathbf{2} \mathbf{b}$ allowed the isolation of pure $\mathbf{2} \mathbf{a}$ and also resulted in the formation of higher amounts of products $\mathbf{2 c}$ and $\mathbf{2 d}$. As hydroperoxides such as $\mathbf{2 c}$ are usually relatively unstable, the reaction was next carried out under the same conditions other than the washing with the reducing agent $\mathrm{Na}_{2} \mathrm{SO}_{3}$ during the workup (Table 1, Entry 3). No significant changes were observable. However, the work-up and purification became more difficult due to a poorer elimination of the remaining oxidant and therefore the time of washing with $\mathrm{Na}_{2} \mathrm{SO}_{3}$ was set to 3 hours with magnetic agitation. Of note, preparation of the 15-hydroxy derivative $\mathbf{2 d}$, in high yields ( $90 \%)$, is possible from $\mathbf{2 c}$ by treatment with either trimethyl phosphite ${ }^{[9]}$ or triphenyl phospine, in dichloromethane.
We also carried out the reaction in the presence of either $\mathrm{NaClO}_{2}$ or TBHP as single reagents (Table 1, Entries 4-5). After 3 days the reaction failed to proceed and the starting material could not be exhausted, thus revealing the need for the combination of both reagents for an effective oxidation of 1 . The same occurred when $\mathrm{NaClO}_{2}$ was tested in catalytic amounts (Table 1, Entry 6) Manipulation of the amounts of oxidant vs time of reaction (Table 1, Entries 7-8) resulted in a shift in the product ratio towards the formation of the hydroperoxide $\mathbf{2 c}$ and slightly higher amounts of 2d. However, with very high amounts of oxidant (4.2 equiv.) and extension of the reaction time to 7 days, a mixture of chromatographically non-separable products formed (data not shown). Previous studies report a single preparation procedure for 2c with an $\mathrm{O}_{2} / \mathrm{NHPI}$ system combined with either cobalt(II) catalyst or $\mathrm{V}-70$, and high yields were achieved only when the 7oxo derivative $2 \mathrm{a}$ was used as the starting material, i.e, with two sequential oxidations. ${ }^{[9]}$ Attempts to oxidize the 7-oxo derivative 2a with the $\mathrm{NaClO}_{2} / \mathrm{TBHP}$-system not only failed to exhaust the starting material but also resulted in an inseparable mixture of various oxidation products. Also, the direct oxidation of $\mathbf{1}$ with catalytic amounts of NHPI in combination with $\mathrm{NaClO}_{2}$ (1.2 equiv.), resulted in reduced yields of the oxidation products $2 \mathbf{a}(24 \%), \mathbf{2 c}$ $(3 \%)$ and $\mathbf{2 d}(4 \%)$ along with $13 \%$ of the starting material. Overall, the reaction conditions described in Table 1, Entry 2, allowed the easy preparation and isolation of products $\mathbf{2 a}$ and $\mathbf{2 c}$, along with minor amounts of $\mathbf{2 d}$.

Table 1. Oxidation of methyl dehydroabietate 1 with $\mathrm{NaClO}_{2} / \mathrm{TBHP}$ in acetonitrile/water (3:1)

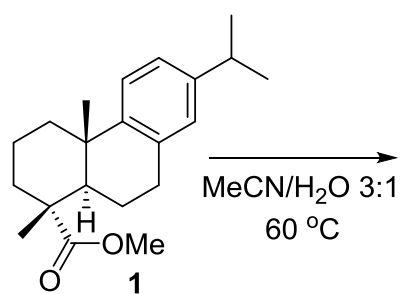

Entry[a]<smiles>COCCC[C@]12CC(=O)c3cc(C(C)C)ccc3C1(C)CCC[C@@]2(C)C(=O)OC</smiles>

Yield (\%)<smiles>COC(=O)[C@]1(C)CCC[C@]2(C)c3ccc(C(C)(C)OO)cc3C(=O)C[C@]21CCC(=O)c1cc(C(C)(C)O)ccc1C</smiles>

Ratio of products (equiv.) (equiv.) (days)

20

$56: 22: 18: 4$

$51: 0: 40: 9$

49:0:38:12

$--[f]$

--_f]

-[-[f]

$35: 0: 52: 14$

37:0:47:16

[a] All reactions were carried out with $0.500 \mathrm{~g}(1.59 \mathrm{mmol})$ of 1 . [b] 20 hours of $\mathrm{Na}_{2} \mathrm{SO}_{3}$ wash. [c] Products $2 \mathbf{2 a}$ and $2 \mathbf{b}$ isolated as a mixture. Product yields [a] All reactions were carried out with $0.500 \mathrm{~g}(1.59 \mathrm{mmol})$ of 1 . [b] 20 hours of $\mathrm{Na}_{2} \mathrm{SO}_{3}$ wash. [c] Products $2 \mathrm{a}$ and $2 \mathrm{~b}$ isolated as a mixture. Product yields
estimated based on the NMR spectrum. [d] Washing with $\mathrm{Na}_{2} \mathrm{SO}_{3}$ was set to 3 hours with agitation. [e] $\mathrm{No} \mathrm{Na}_{2} \mathrm{SO}_{3}$ washing during the work-up procedure. [f] No exhaustion of the starting material. 


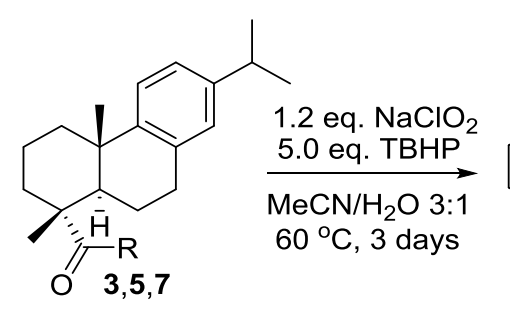<smiles>CC(C)c1ccc2c(c1)C(=O)CC1(C)CCCC(C)(C(=O)O)C1C2(C)C</smiles>

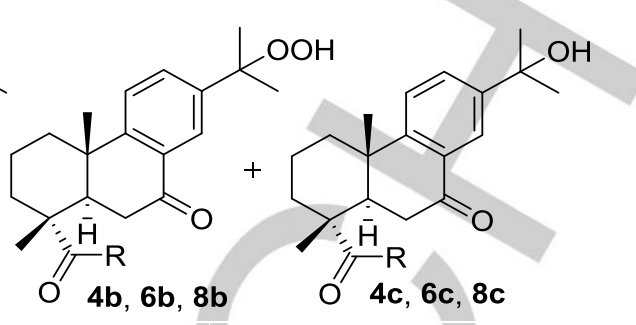

\begin{tabular}{ccccccccc} 
Substrate $^{[a]}$ & $\mathrm{R}$ & Product & Yield (\%) & Product & Yield (\%) & Product & Yield (\%) & Ratio of products \\
\hline $\mathbf{3}$ & $\mathrm{NH}_{2}$ & $\mathbf{4 a}$ & 30 & $\mathbf{4 b}$ & 9 & $\mathbf{4 c}$ & 13 & $58: 17: 25$ \\
$\mathbf{5}$ & $\mathrm{NHCH}_{2} \mathrm{CO}_{2} \mathrm{Me}$ & $\mathbf{6 a}$ & 38 & $\mathbf{6 b}$ & 15 & $\mathbf{6 c}$ & 5 & $66: 26: 9$ \\
$\mathbf{7}$ & $\mathrm{NMe}_{2}$ & $\mathbf{8 a}$ & 35 & $\mathbf{8 b}$ & 26 & $\mathbf{8 c}$ & 6 & $52: 39: 9$ \\
\hline
\end{tabular}

[a] All reactions were carried out with $0.500 \mathrm{~g}$ of the starting material.

As 1 remains to date the only extensively studied starting material for the benzylic oxidation of dehydroabietanes, we tested the reaction on other dehydroabietic acid derivatives (Table 2). We found that the method was suitable for the oxidation of primary 3 , secondary $\mathbf{5}$ and tertiary amides $\mathbf{7}$ and the oxidation pattern was similar to the one observed with methyl dehydroabietate 1 . The oxidation of 3 formed slightly smaller amounts of 7-oxo-15hydroperoxy product $\mathbf{4 b}$ than that of 5 and 7 , suggesting that $\mathbf{4 b}$ is probably less stable.<smiles>[R]C(=O)[C@]1(C)CCC[C@]2(C)c3cc([R])c(C(C)C)cc3CC[C@]21C</smiles>

9, $\mathrm{R}^{1}=\mathrm{OH}, \mathrm{R}^{2}=\mathrm{H}$

11, $R^{1}=$ OMe, $R^{2}=A C$

13, $\mathrm{R}^{1}=\mathrm{NH}_{2}, \mathrm{R}^{2}=\mathrm{Ac}$

15, $\mathrm{R}^{1}=\mathrm{NMe}_{2}, \mathrm{R}^{2}=\mathrm{Ac}$

17, $\mathrm{R}^{1}=\mathrm{OMe}, \mathrm{R}^{2}=\mathrm{OMe}$ a

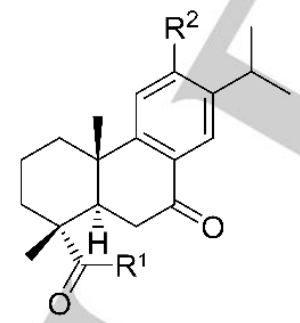

10, $\mathrm{R}^{1}=\mathrm{OH}, \mathrm{R}^{2}=\mathrm{H}, 42 \%$

12, $\mathrm{R}^{1}=\mathrm{OMe}, \mathrm{R}^{2}=\mathrm{Ac}, 81 \%$

14, $\mathrm{R}^{1}=\mathrm{NH}_{2}, \mathrm{R}^{2}=\mathrm{Ac}, 52 \%$

16, $R^{1}=\mathrm{NMe}_{2}, \mathrm{R}^{2}=\mathrm{Ac}, 51 \%$

18, $\mathrm{R}^{1}=\mathrm{OMe}, \mathrm{R}^{2}=\mathrm{OMe}, 74 \%$
Scheme 1. Regioselective oxidation of aromatic abietanes $9,11,13,15$, and 17. Reagents and conditions: a) $\mathrm{NaClO}_{2}$ (1.2 equiv.), TBHP (5.0 equiv.), $\mathrm{MeCN} / \mathrm{H}_{2} \mathrm{O}(3: 1), 60^{\circ} \mathrm{C}, 3 \mathrm{~d}$.

To further investigate the scope of this method, we attempted next the direct oxidation of 9 (Scheme 1). Surprisingly, only the 7-oxo derivative 10 was obtained, in $42 \%$ yield, after purification by column chromatography. We reasoned that the high polarity of the oxidation products formed, which hampers chromatographic purification, as well as the partial degradation of $\mathbf{9}$ during the reaction, account for the observed results and yield. Nonetheless, the fact that compound 9 could be directly oxidized with this method to give a single reaction product, albeit in moderate yield, is encouraging as previous studies report only the use of chromium(VI)-based reagents for this transformation.

A free radical mechanism is generally accepted for hydroperoxide- and chlorite-mediated allylic/benzylic oxidations and a determinant step is the formation of carbon radicals which can further react to form oxygenated products. ${ }^{[2,21]}$ To confirm the reaction mechanism, an experiment was run with the conditions in Table 1, Entry 2, in the presence of the radical inhibitor butylated hydroxytoluene (BHT, 50 mol\%). After 3 days, starting material was recovered along with small amounts (14\%) of the 7 oxo product $2 \mathrm{a}$, clearly indicating that the oxidation is hampered by the presence of BHT.

In the course of this study, we consistently observed a higher reactivity at $C 7$ for compounds $1,3,5$, and 7 that differ in the functional group present in ring $A$. Therefore, we addressed the effect of ring $C$ substitution on the reaction outcome next by oxidizing the 12-substituted compounds 11, 13, 15 and 17. As shown in Scheme 1, during the oxidation of the 12-acetyl derivative 11, a single product formed that corresponded to the 7oxo derivative 12 , and was isolated in $81 \%$ yield. The observed regioselectivity and yield after chromatographic purification were remarkable as oxidation of this compound with different amounts of $\mathrm{CrO}_{3}$ (3.0-3.5 equiv.) fails to provide compound $\mathbf{1 2}$ in yields higher than $53 \%$. The reaction was further tested on the 12-acetyl derivatives 13 and 15 and the respective 7-oxo products 14 and 16 were isolated as the single reaction products, in $52 \%$ and $51 \%$ yields, respectively, after chromatographic purification. Finally, the 12-methoxy derivative $\mathbf{1 7}$ was prepared to verify whether the outcome of the reaction would change by introduction of an electron-donating group at $\mathrm{C} 12$. However, the oxidation of 17 also gave a single 7-oxo product 18 (Scheme 1).

To account for the observed regioselectivity, a theoretical computational study was made where the stability of the 
dehydroabietyl radicals at C7 and C15 of compounds 1, 11 and 17 was calculated by ab initio computational studies at the B3LYP/6-31G(2d,p) level (Table 3). The study revealed that the free energy at $298 \mathrm{~K}$ of the $\mathrm{C} 7$ radical is lower than that of the $\mathrm{C} 15$ radical which can explain the preferential oxidation at $\mathrm{C} 7$. Moreover, the energy difference between the $\mathrm{C} 7$ and the $\mathrm{C} 15$ radicals is much higher for compounds $\mathbf{1 1}$ and $\mathbf{1 7}$ than for compound 1, which supports the observation that only the 7-oxo derivatives are formed in the case of the 12-substituted substrates.

Table 3. Thermochemical calculations of model radicals free energies (values reported for Gibbs energy at $298 \mathrm{~K}$ )

Compound

11

17

The utility of this procedure for the semisynthesis of the naturally occurring picealactones $\mathrm{A}, \mathrm{B}$ and $\mathrm{C}$ was next demonstrated. These picealactones were isolated from the heartwood of Picea morrisonicola Hayata ${ }^{[21]}$ and bear a 5-dehydro-18,6-olide moiety common to the ent-kaurane stevionolide from Stevia lucida Lag. ${ }^{[23]}$ A previous report concerns their preparation from abietic acid $^{[9,24]}$ but their biological activity has not been investigated to date.
As depicted in Scheme 2, after preparation of intermediates $\mathbf{1 0}$ and $\mathbf{2 d}$ by means of the $\mathrm{NaClO}_{2} / \mathrm{TBHP}$ oxidation, the picealactones A 20 and B 22 were prepared, in a sequential synthesis, using a modification of the procedure of Korovin et al., ${ }^{[25]}$ by bubbling air into the reaction mixture containing the respective substrates in the presence of potassium tert-butoxide in tert-butanol. The resulting crude reaction mixture contained diosphenol 19 (21) and a small amount of the desired lactone 20 (22) which after treatment with 1-ethyl-3-(3dimethylaminopropyl)carbodiimide (EDC) hydrochloride, gave the desired picealactones A (20) and B (22) as single products (54\% and $55 \%$ yields, respectively, after purification by column chromatography). Overall, the picealactones A 20 and B 22 were synthesized from the commercially available starting material 9 in 3 and 4 steps, respectively, and their structures were confirmed by single crystal $\mathrm{X}$-ray studies after recrystallization from methanol. Picealactone $C(25)$ was synthesized similarly by bubbling air into the reaction mixture of $\mathbf{1 8}$ and potassium tertbutoxide in tert-butanol giving a mixture of $\mathbf{2 3}$ and $\mathbf{2 4}$ which was treated with EDC hydrochloride to give $\mathbf{2 4}$ as a single reaction product. Hydrolysis of $\mathbf{2 4}$ with boron tribromide gave the desired picealactone C 25 in a total yield of $39 \%$, over 4 steps (Scheme 3). A screening of the anti-proliferative properties of the picealactones using prostate (PC-3) and breast (T47D) cancer cell lines revealed that picealactones $A \mathbf{2 0}$ and $C \mathbf{2 5}$ inhibited the proliferation of breast cancer cells lines with $\mathrm{IC}_{50}$ values close to $10 \mu \mathrm{M}$ and can be regarded as good starting materials for further optimization in pursuit of new agents to target endocrine cancers (Supporting Information).

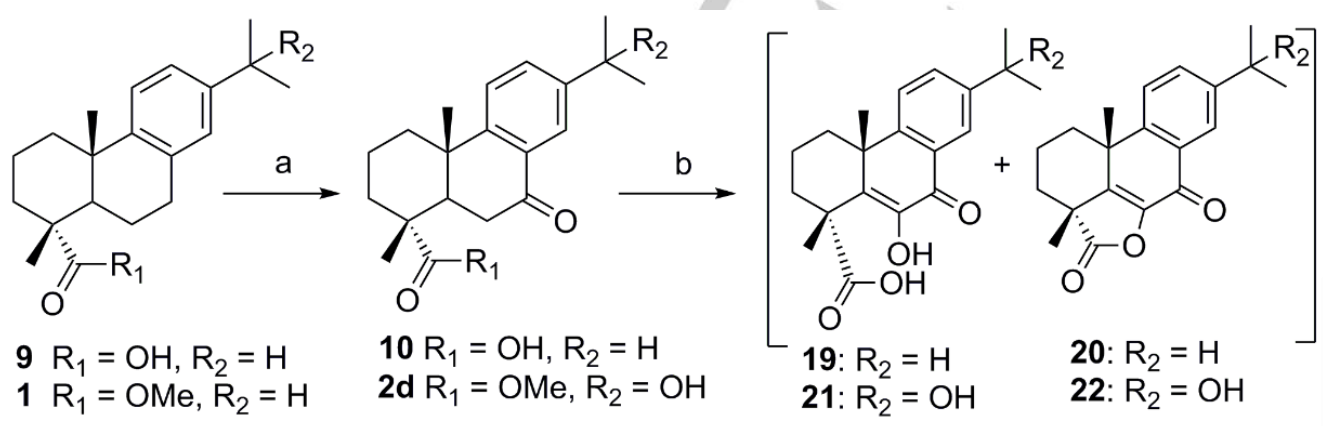<smiles>[R20][R2](=O)OC1=C2C(=O)c3cc(C([R2])(C)C)ccc3[C@@]3(C)CCC[C@](C)(C(=O)O3)C2=C1</smiles>

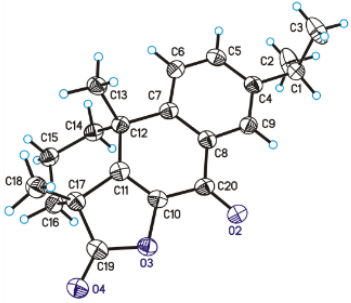

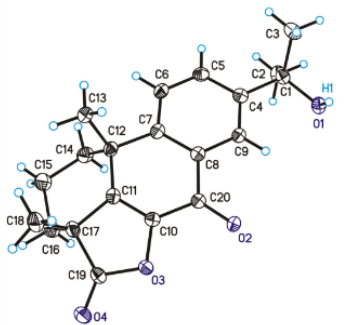

Scheme 2. Short-step syntheses of picealactones $A(20)$ and $B$ (22). Reagents and conditions: a) $\mathrm{NaClO}_{2}, \mathrm{TBHP}, \mathrm{MeCN} / \mathrm{H}_{2} \mathrm{O}(3: 1), 60{ }^{\circ} \mathrm{C}, 3 \mathrm{~d}, 42 \%(\mathbf{1 0}), 7 \%(\mathbf{2 d})$; b) air, $t$-BuOK, $t-\mathrm{BuOH}, 35^{\circ} \mathrm{C}, 2-4 \mathrm{~h}$; c) EDC hydrochloride, DMAP, $\mathrm{CH}_{2} \mathrm{Cl}_{2}, 0^{\circ} \mathrm{C} \rightarrow \mathrm{rt}, 2 \mathrm{~h}, 54 \%$ (20), 55\% (22) (yields over 2 steps). 
<smiles>COC(=O)[C@]1(C)CCC[C@]2(C)c3cc(OC)c(C(C)C)cc3CCC2[C@]1(C)CCC[C@]1(C)CCC(=O)c2cc(C(C)C)c(OC)cc21</smiles>

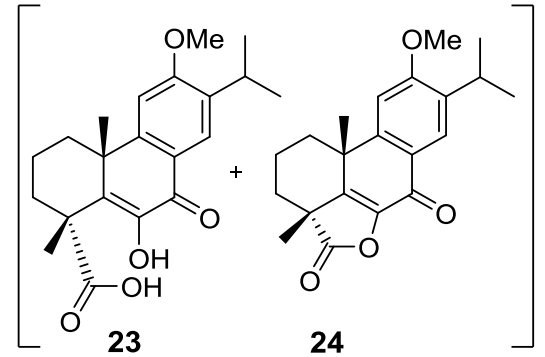

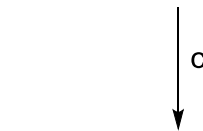<smiles></smiles>

d

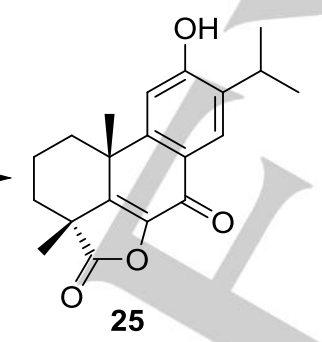

25

Scheme 3. Synthesis of picealactone $\mathrm{C}(25)$. Reagents and conditions: a) $\mathrm{NaClO}_{2}, \mathrm{TBHP}, \mathrm{MeCN} / \mathrm{H}_{2} \mathrm{O}(3: 1), 60{ }^{\circ} \mathrm{C}, 3 \mathrm{~d}, 74 \%$; b) air, $t$-BuOK, $t-\mathrm{BuOH}, 35$ ${ }^{\circ} \mathrm{C}, 3.5 \mathrm{~h}$; c) EDC hydrochloride, DMAP, $\mathrm{CH}_{2} \mathrm{Cl}_{2}, 0^{\circ} \mathrm{C} \rightarrow \mathrm{rt}, 2.5 \mathrm{~h}, 71 \%$ (yield over 2 steps); d) $\mathrm{BBr}_{3} \mathrm{CH}_{2} \mathrm{Cl}_{2}, 0^{\circ} \mathrm{C}, 6 \mathrm{~h}, 75 \%$.

\section{Conclusions}

In summary, the $\mathrm{NaClO}_{2} / \mathrm{TBHP}$ system is a convenient, ecofriendly and inexpensive method for the preparation of 7-oxo, 7oxo-15-hydroperoxy and 7-oxo-15-hydroxy derivatives of aromatic abietanes. It allows the direct oxidation of several dehydroabietanes bearing different functional groups such as carboxyl, carbonyl, amide and methoxide, via a radical-mediated reaction mechanism. Moreover, for 12-substituted aromatic abietanes, the method is regioselective and gives the 7-oxo derivatives exclusively, in good yields. This work conveniently replaces chromium(VI)-based reagents for these transformations and provides an easy access to key reaction intermediates that can be used in the semisynthesis of naturally occurring diterpenoids, otherwise inaccessible for further studies in the

development of new drugs. We believe our work will be considered of general utility and become widely adopted by those working in the field of diterpenoids chemistry.

\section{Supporting Information Summary}

Compound spectra and experimental procedures. Thermochemistry, single crystal X-ray crystallographic data and MTT assay data.

\section{Acknowledgements}

L.K., V.M.M and J.Y.-K. acknowledge the University of Helsinki Research Foundation and the Academy of Finland (Projects 264020 and 265481) for financial support. S.M.S. and V.B. acknowledge the POCI-COMPETE 2020 (Project POCI-01-0145FEDER-007491) and the Portuguese Foundation for Science and Technology (Project UID/Multi /00709/2013).

Keywords: abietic $\cdot$ benzylic oxidation - eco-friendly picealactone $\cdot$ regioselective

[1] M. A. González, Nat. Prod. Rep. 2015, 32, 684-704.

[2] L. Yang, L. Qiao, C. Ji, D. Xie, N. B. Gong, Y. Lu, J. Zhang, J. Dai, S. Guo, J. Nat. Prod. 2013, 76, 216-222.

[3] S. Mahdjour, M. Harche-Kaid, A. Haidour, R. Chahboun, E. Alvarez Manzaneda, Org. Lett. 2016, 18, 5964-5967.

[4] H. Benelkebir, A. M. Donlevy, G. Packhama, A. Ganesan, Org. Lett. 2011 13, 6334-6337.

[5] L. Gerstmann, M. Kalesse, Chem. - Eur. J. 2016, 22, 11210-11212

[6] M. C. Carreno, J. L. G. Ruano, M. A. Toledo, Chem. - Eur. J. 2000, 6 288-291.

G. Wen, S. Wang, Eur. J. Med. Chem. 2010, 45, 4692-4696.

[8] W. Gu, C. Qiao, S-F. Wang, Y. Hao, T-T Miao, Bioorg. Med. Chem. Lett. 2014, 24, 328-331.

[9] Y. Matsushita, K. Sugamoto, Y. Iwakiri, S. Yoshida, T. Chaen, T. Matsui Tetrahedron Lett. 2010, 51, 3931-3934.

[10] E. J. Alvarez-Manzaneda, R. Chahboun, J. J. Guardia, M. Lachkar, A Dahbouh, A. Lara, I. Messouri, Tetrahedron Lett. 2006, 47, 2577-2580.

[11] P. F. Ritchie, T. F. Sanderson, L. F. McBurney, J. Am. Chem. Soc. 1954 76, 723-726.

[12] S. M. C. S. Monteiro, A. J. D Silvestre, A. M. S. Silva, J. A. S. Cavaleiro, V. Félix, M. G. B. Drew, New J. Chem. 2001, 25, 1091-1097.

[13] J. A. S. Cavaleiro, G. M. S. F. C. Nascimento, M. G. P. M. S. Neves, M. T. Pinto, A. J. D. Silvestre, M. G. H. Vicente, Tetrahedron Lett. 1996, 37, 1893-1896.

[14] B. Gigante, M. J. Marcelo-Curto, A. M. Lobo, S. Prabhakar, A. J. Slawin H. S. Rzepa, D. J. Williams, J. Nat. Prod. 1989, 52, 85-94.

[15] K. Uneyama, T. Katayma, S. Torii, Bull. Chem. Soc. Jpn. 1987, 60, $3043-$ 3044.

[16] W.-S. Li, J. D. McChesney, J. Pharm. Sci. 1992, 81, 646-651.

[17] P. F. Ritchie, T. F. Sanderson, L. F. McBurney, J. Am. Chem. Soc. 1953, 75, 2610-2612.

[18] I. Fabian, Coord. Chem. Rev. 2001, 216-217, 449.

[19] P. Marwah, A. Marwah, H. A. Lardy, Green Chem. 2004, 6, 570-577.

[20] S. M. Silvestre, J. A. R. Salvador, Tetrahedron 2007, 63, 2439-2445. 
[21] Y. Li, X. Wu, T. B. Lee, E. K. Isbell, E. J. Parish, A. E. V. Gorden, J. Org. Chem. 2010, 75, 1807-1810.

[22] Y.-H. Kuo, M.-H. Yeh, Lin, H.-C. Chem. Pharm. Bull. 2004, 52, 861-863.

[23] J. M. Amaro-Luis, Phytochemistry 1993, 32, 1611-1613.

[24] E. Alvarez-Manzaneda, R. Chahboun, E. Cabrera, E. Alvarez, R. Alvarez-Manzaneda, M. Lachkar, I. Messouri, Tetrahedron Lett. 2007, 48, 989-992.

[25] A. V. Korovin, A. V. Tkachev, Russ. Chem. Bull. 2001, 50, 304-310. 


\section{Entry for the Table of Contents}

\section{FULL PAPER}
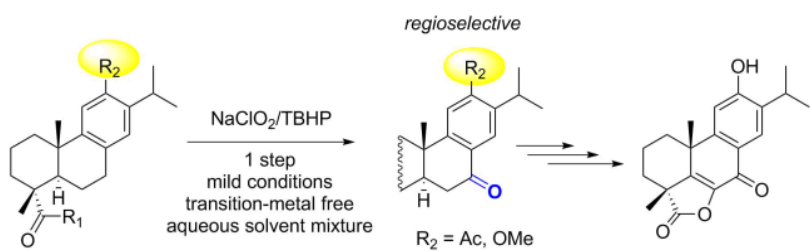

Benzylic oxidations: The regioselective benzylic oxidation of aromatic abietanes is accomplished by a system comprising of sodium chlorite and aqueous tert-butyl hydroperoxide. The method obviates the need for chromium(VI)-based reagents for this transformation and provides an easy access to versatile intermediates for the synthesis of bioactive diterpenoids.
Laura E. Kolsi, Sara Krogerus, Vanessa Brito, Dr. Tobias Rüffer, Prof. Heinrich Lang, Prof. Jari Yli-Kauhaluoma, Dr. Samuel M. Silvestre, Dr. Vânia M. Moreira*

\section{Page No. - Page No.}

Regioselective Benzylic Oxidation of Aromatic Abietanes: Application to the Semisynthesis of the Naturally Occurring Picealactones A, B and C 